\title{
The Postwar Economic System in Germany: Creation, Evolution, and Reappraisal
}

\author{
by DIETER DUWENDAG
}

\begin{abstract}
Professor Duwendag is a professor of economics at the University of Speyer (Hochschule fuir Verwaltungswissenschaften), Speyer, Germany. He received his Ph.D. in economics from the University of Miinster and taught at the University of Köln prior to his appointment at Speyer. Professor Duwendag has published ntwerous articles dealing with stabilization policy in Germany.

The following article is a capsule presentation of the evolution of the German economic system since World War II and of the discussions about the degree of government involvement in the German economy. Since the latter is an issue which is being actively discussed in the United States, it might be helpful to see how this debate has progressed in Germany.

Professor Duwendag is on leave from the University of Speyer and was a visiting scholar at the Federal Reserve Bank of St. Louis from March to mid-July.
\end{abstract}

\begin{abstract}
A AVE of pessimism regarding current economic conditions appears to have afflicted many parts of the world. Such pessimism manifests itself in skepticism regarding market type economic systems and democratic forms of government in general. In other words, the extent of government involvement in the functioning of the economy seems to be a major issue.
\end{abstract}

In the United States, for example, there are those who consider the recent less-than-desirable economic performance to be the result of incorrect and misdirected decisions on the part of the private sector. These critics of free markets, therefore, advocate the replacement of many private sector decisions by more government decisions in the form of government planning.

On the other side there are those who regard current economic problems as a result of too much government involvement in the economic system. They cite, for example, all the government regulations which impinge on the ability of private enterprise to make sound business decisions. In addition, these opponents of government involvement in the economy maintain that attempts on the part of the government to "fine tune" the economy have been counterproductive.

In order to evaluate the merits of the two conflicting viewpoints, it would be useful to examine an economic system that evolved as a result of active consideration of both views. Such an example exists in Germany where, since World War II, the debate

NOTE: This article was translated from German by Hans Helbling. over the role of government in a market oriented economic system has made a significant contribution to the economic system which currently prevails.

\section{PHASES OF EVOLUTION OF TUE GERMAN ECONOMY}

From its inception at the end of World War II to the present, the economic system in Germany has undergone change. Three phases of change may be identified:

1) establishment of a market economy that remained essentially unchanged throughout the reconstruction period, which lasted until about 1960 ;

2) reaction of the state to rectify market imperfections since about 1960

3) reappraisal of the market system's efficiency the phase which is currently in progress.

The economic system in all three phases may be described as a mixed economy - that is, a system in which both the private and public sectors affect the allocation of resources. The theoretical base for this economic system lies in neo-liberal ideas whose main German-speaking proponents were W. Eucken, A. von Hayek, and A. Muiller-Armack. These economists strongly influenced the "spirit" of the German constitution of 1949 as well as the formulation of economic policy. From the outset there was a consensus among all major political groups regarding the establishment of a market type economic system which was "socially responsible".

In such an environment, the role of government is expanded beyond the basic function of providing a 
democratic (legal and institutional) framework which, among other things, protects individual freedoms. Other responsibilities are the allocation of resources (providing public goods), the stabilization of the economy, and the redistribution of income and wealth. ${ }^{1}$ By assuming these responsibilities, it is hoped that the government may also be able to prevent the concentration of economic power, promote self-help initiatives, and correct undesirable market induced results in general.

\section{Postuar Reconstuction Phase}

After decades of experience with central planning, the introduction of democratic and market system principles after the end of World War II was like a voyage into uncharted waters. A feeling for democracy and for a market oriented economic system had by and large disappeared. Thus, the new system of socioeconomic organization was regarded by many as an experiment. Doubt was expressed as to whether the German population would be able to adapt to the new conditions. In retrospect, however, it can be said that the adaptation proceeded more quickly than even optimists had thought possible.

The first postwar phase of the German economy was characterized by reconstruction, the elimination of other war-induced problems, and the absorption of more than 10 million refugees from former German territories in the east. The economic results of the reconstruction phase, until approximately 1960 , became widely known as "the German economic miracle." It featured reduction of the unemployment rate from 11 percent in 1950 to 1 percent in 1960, above average economic growth, practically stable prices, and high and increasing export surpluses.

The German economy grew at a rapid rate because ample capacity (capital and labor) existed. With the exception of the agricultural sector, which had come under increasing governmental control after the establishment of the EEC in 1958, many of the remaining government regulations - especially on land and housing - had been lifted by 1960 . Thus in the postwar reconstruction phase the economy was essentially a free market system with variability of individual prices and open entry to all economic sectors. Democracy and the market economy had withstood their first crucial test. Stable political conditions and efficient economic results indicated that the decision

1Richard A. Musgrave, The Theory of Public Finance: A Study in Public Economy (New York: MeGraw-Hill Book Company, Inc., 1959 ). regarding the establishment of the new system had been appropriate.

Despite the success of the reconstruction phase, some problems remained. Rapid economic growth did not proceed without frictions and excesses. The provision of certain public goods (one of the social elements of the market economy) had been neglected, according to many. ${ }^{2}$ (1) Following the breakup of cartels after World War II, new power constellations developed, especially in the heavy industries (iron, coal, and steel), the chemical industry and the banking sector. In addition, new power concentrations arose in the construction industry and the retail sector at the expense of small and medium sized firms. It was felt by some that these developments endangered competition. (2) The functional income distribution remained practically constant from 1950 until 1960 (wage share 0.6; profit share 0.4). (3) Severe cyclical swings in economic growth raised questions concerning the stability of the private sector.

To sum up, the new system of social and economic organization was considered still in its infancy. At this point government guidance was favored as a means of assuring full development of the potential benefits of the newly evolved market system.

\section{State Reaction Phase}

The second phase of the German postwar development extends to the present, and thus overlaps with the third phase. Government reacted to the problems of the first phase in four ways. These reactions, in turn, impinged somewhat on economic freedom.

(1) Competition and Restrictions on Business: The law governing cartels was strengthened and firms with market power became subjected to stronger regulations by the Federal Agency for Cartel Supervision (Bundeskartellamt). In spite of these actions, the number of German firms declined by about 300,000 (15 percent) from 1961 to 1970 , and this decline affected almost solely small firms (up to 49 employees). In addition, occupational and product safety legislation became more stringent. And in recent times new environmental regulations were devised with the aim of requiring producers to assume (internalize) costs of production which had before fallen on others.

(2) Progressively Increasing Public Expenditures: As shown in the accompanying chart, the proportion of GNP accounted for by total Government expenditures

2 For a distinction between private and public goods, see Paul A. Samuelson, "The Pure Theory of Public Expenditure," The Review of Economics and Statistics (November 1954), p. 387 . 


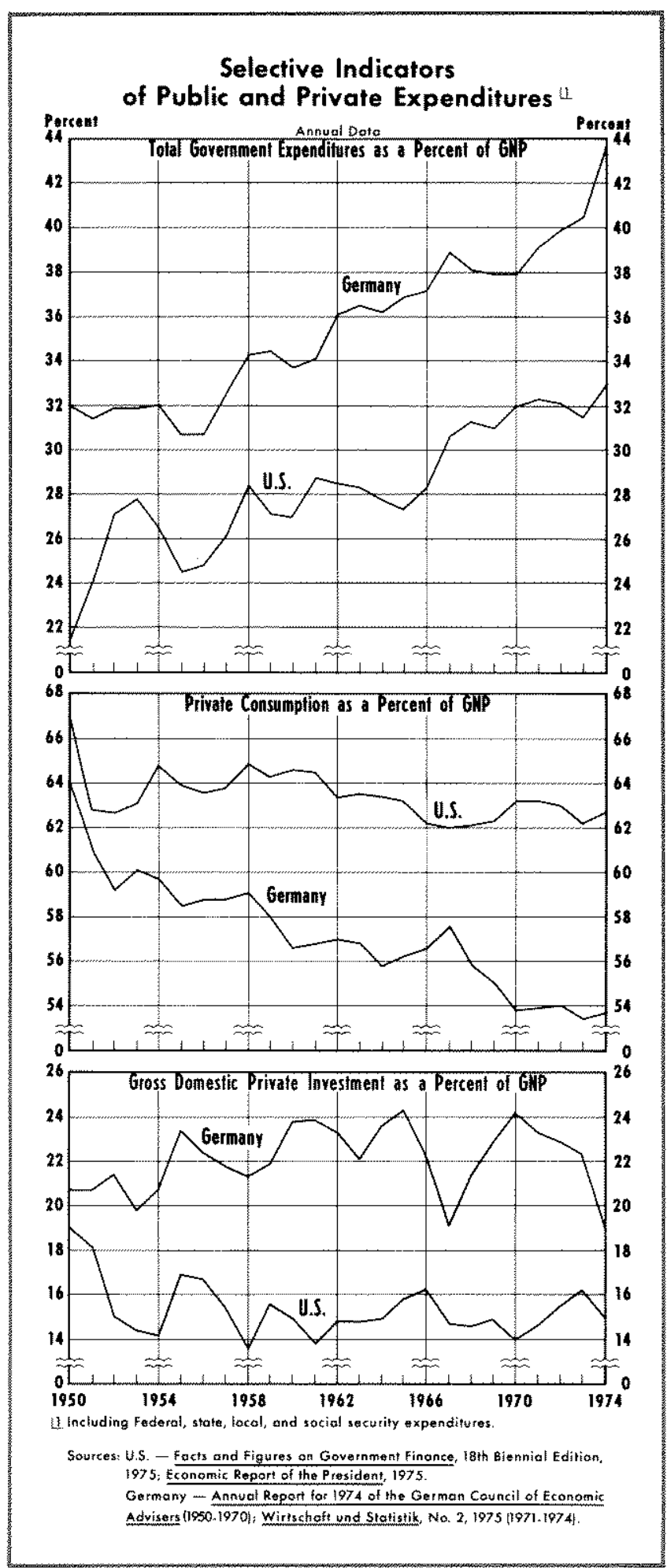

in Germany increased from 32 percent in 1950 to 43.6 percent in 1974. The rising pace of increase in these expenditures is especially remarkable; 1.7 percentage points from 1950 to $1960,4,2$ percentage points from 1960 to 1970 , and 5.7 percentage points from 1970 to 1974. Thus, in the last four years alone, the increase in government expenditures amounted to approximately the same absolute increase which occurred during the previous twenty years. As a result, the proportion of GNP accounted for by private consumption decreased noticeably. Developments in the United States show similar tendencies, even though the share of government expenditures of GNP is significantly smaller than in Germany.

The progressively increasing government expenditures are, at least partly, the monetary reflex of changed government responsibilities. They are reflected, on the one hand, by an expanded infrastructure (transportation, communication, education, etc.), a larger supply of public goods in general, and in sectoral and regional policy measures. Such measures were to aid specific regions, to subsidize sectors of national importance (coal, railways, postal service) and to neutralize crowding out effects on small and medium sized firms as a consequence of the newly established economic power constellations mentioned above. Also, increased Government activity occurred in such areas as the social security system (increased contributions), tax laws (tax rate increases for higher income classes, tax rate reductions for lower income groups), and wealth redistribution in the form of subsidized savings programs for lower income groups. Thus, redistribution policies in Germany, together with more active labor unions, led to an increase in the wage share from 60 percent in 1960 to 70 percent in $1973 .^{3}$

(3) Stabilization Policies: Toward the end of the 1960s five complete growth cycles had been experienced and inflationary tendencies had manifested themselves with the result that energetic governmental guidance of economic activity ensued. An important force for the ratification of the "Stabilization and Growth Law" of 1967 was the recession of 1966/1967. This law provided for a broad spectrum of anticyclical instruments of tax and expenditure policies to be invoked in case of - as stated by the law - an "impending economic disequilibrium". Until 1967 there was no conscious attempt of using anticyclical policies.

The Stabilization and Growth Law requires that policies of Federal, state, and local governments do not jeopardize overall economic equilibrium. Unlike the U.S. Employment Act of 1946, however, the German central bank is not included in the above requirement. The law defines "economic equilibrium" as a condition in which the goals of price stability, high

\footnotetext{
${ }^{3}$ Labor mions had become progressively active, demanding not only compensation for inflation but also a higher share of the total income change.
} 
employment, balance of payments equilibrium, as well as continuous and reasonable economic growth are satisfied simultaneously. In case the actual situation deviates from this optimal combination of goals, or in case conflicts between the individual goals arise, the executive branch of the Federal government decides about the type and extent of fiscal measures to resolve the conflicts and to maintain the optimal goal combination.

The instruments of this law, especially public investment programs and changes in the income tax and depreciation rates, have been used against both inflation and recession. A slogan which accompanied the formulation of this law was: "as much market as possible, as much planning as necessary". The intention was for this law to affect macroeconomic relations only, whereas the market mechanism was to be the sole means of affecting microeconomic relationships. From the beginning there was criticism that such a distribution of responsibilities between government and market was not feasible, and perhaps even contradictory. Moreover, the philosophy on which the law was based was strongly attacked. The underlying philosophy of the law postulated that market systems have inherent tendencies to increase cyclical disturbances to such an extent that the system itself may be endangered - a hypothesis which remains unsupported.

(4) Market Intervention: An additional distinguishing feature of the reaction phase of government was that certain sectors (the market for rental property, and portions of the markets for land and energy) were taken out of the free market and subjected to govermmental price and/or quantity controls. Such a move was generally motivated by above average price increases in those particular sectors.

\section{Teappraisal of Market System Phase}

While the second phase was characterized by increasing govermment expenditures, a third phase which appears to be emerging is characterized by increased anxiety about government activity. Some feel that government involvement in the economy has advanced so far as to seriously endanger economic freedom in particular and the market system in general. Those concened with this development demand reductions of both governmental controls and intervention and also call for a reappraisal of the merits of the market system. Such demands have become more pronomeed in recent years as a result of intense public discussion and of new political initiatives involving governmental guidance of private investment decisions and the requirement to have workers participate in the corporate decisionmaking process (known as "democratization of employer decisions"). In general, those opposed to the growth of government base their arguments primarily on the following:

(1) Deductions for taxes and social security amounting to approximately 40 percent of GNP lead to both a diminished willingness to work and to a general welfare mentality. Since more and more private sector functions are assumed by the public sector, the functioning of the market system is jeopardized. Bureancratic administration of profits and losses is increasingly substituted for profit and loss decisions made in the market.

(2) The Keynesian doctrine, which advocates smoothing of the business cycle through fiscal actions, is not supported by the German experience. On the contrary, the opposite thesis has to be entertained, namely that the use of policy instruments (implementation of the Stabilization and Growth Law) worked in such a way as to increase cyclical disturbances.

In fact, a number of undesirable results materialized after implementation of the new law in 1967. Even though the law was designed to affect macroeconomic processes only, microeconomic effects resulted in practice. Restrictive policy actions, for example, led to discrimination against small and medium sized firms. The reason for this was that because of a lack of diversification such firms were affected more by a cutback of government orders than large cor. porations. On the other hand, during periods of expansionary fiscal policy large corporations were able, because of skilled management, to react to changes in tax and depreciation rates much faster than small and medium sized firms.

Once such selective micro effects had manifested themselves, specific governmental programs were required to correct the effects of previous fiscal actions. In other words, fiscal policy assumed an ad hoc char. acter, based on the principle of trial and error. There were also the more general problems associated with fine tuning, and the lagged response of the economy to policy actions which increased both the uncertainty of private sector decisions and the size of the public sector.

(3) Finally, price controls over the markets for land and rental property generated sharp criticism. Since all sectors of the economy are interdependent, government control of prices in one sector will necessarily affect other sectors also. Once begun, governmental intervention, like an oil spill on water, tends to spread 
to more and more markets, but first to the most closely related sectors. With respect to the markets for land and rental property, the most closely related sectors, (and, hence, likely candidates for the imposition of controls), would be the construction industry and capital markets. Germany is now once again at a point where she is trying to decide what degree of government involvement will give desired results without impinging on the benefits derived from the free market.

\section{IN SEAPCH OF AN OPTMAL MIX BETWEEN PRYVATE AND PUBLIC SECTOR}

In an economy where private and public sectors coexist, the question arises whether there is an optimal combination between the two. This question may be analyzed by considering at governmental action regarding the assumption of new responsibilities (for example, environmental conservation). The life cycle of such a decision may be characterized as follows:

The starting point is $w h y$ should government assume this responsibility? A common answer might be: because desires for this service exist. This answer immediately provokes several other questions: how is it possible to determine whether this service is desired? Would the private sector be less efficient at providing these services? Or, are we concerned about goods and services which the private sector won't provide either not at all, or in insufficient quantities (too high a cost)? Is the decision perhaps based on political considerations?

Assuming the government, after considering its constitutionality, decides to accept the new responsibility, the next step would be to inquire into the consequences of this decision. Responsibility for this serv. ice necessitates expenditures (for salaries, goods, and perhaps transfer payments). These expenditures, in tum. have consequences for the development and the structure of the markets for goods, services and factors of production (allocation of resources).

Finally, it is necessary to decide on the method of financing the new expenditures (user charges, contributions, taxes or credit). Which is preferred, depends on legal, political and economic considerations.

The fundamental question in this connection concerns the "appropriate" (optimal) proportions of private and public goods in a (principally) market oriented economy. Answering this question requires a theoretical basis, a general theory of optimal state activity, that is, a theory of public responsibilities.

\section{Analytical Approach}

An exact criterion for determining the optimal quantities of both public and private goods supplied would be a social welfare function. Such a function should contain all privately and publicly produced goods and services (as well as their distribution among individuals) as arguments. If it were possible to find a yardstick with which to measure the supply of public goods objectively, and if a social welfare function were available, it would be possible to determine the optimal supply of public goods for any available quantity of resources. Research on the construction of an empirical welfare function has been going on for more than 100 years, and so far has been, and will probably remain, unsuccessful.

This approach is based on principles of price and utility theory, which conclude that the last unit of money spent will result in the same utility in all its uses.t In other words, if the additional utility of a dollar spent on public goods exceeds that of private goods, then this dollar should be channeled to the public sector in order to maximize social welfare. Although plausible, this approach does have serious drawbacks.

Since interpersonal and intertemporal utility comparisons can not be used as objective yardsticks, the evaluation of the supply of public goods can only be made on the basis of subjective preferences. ${ }^{5}$ Different groups of society - in the extreme each individual - will, therefore, consider a different combination of total supply as optimal. In addition, there is the complication that the output of public goods is either imperfectly, or not at all, measurable (see screened insert). An empirical social welfare function is therefore difficult, if not impossible, to come by; it is an abstract theoretical concept. The failure to develop an empirical social welfare function was described by one of the leading welfare theoreticians, K. E. Boulding, as follows: "I believe this attempt has been a failure, though a reasonably glorious one. ..." Thus, the absence of objective guidelines with which to evaluate state responsibilities has led in recent years to increasing anxiety over state activities.

\footnotetext{
4 For a lucid evaluation of this approach, see Francis M. Bator, "Simple Analytios of Welfare Maxinization," The American Economic Review (March $195 \%$ ), pp. 22-59.

see E. I. Mishan, Welfare Economics (New York: Random House, 1964).

"Kenneth E. Boulding, "Economics As A Moral Science," The American Economic Review (March 1969), p. 5 .
} 


\section{Measurement of State Activity}

Today there is fear that the Federal Republic is moving relentessly in the direction of a "welfare state, it la Seandinatian examples. However the de: Gree of state atthity ipon which such fidguents are based is usually expressed by economic tariables, and can leat, depending on 7 he chicice of the particulat variable, to different comdisions. According to the accompanying chatt with data for 1974, Were are at least tiree different varkbles which tan serve as pruxies for the degree of state ietivity f relative to (ANP:

- The broadte defmed indicator of state activity (C: $=43.6$ percent for the U.S. C. 33 percent):

- The less brodly defned ndicator (exchuding transfer pamments) $\left(C=C^{*}\right.$. $T t=23.5$ percent: for the U.S. $C=91.4$ percent in 1973 ).

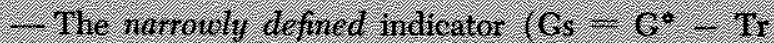
$G$ G $=10.6$ percent, for the US. Gs. 11.5 percent (1) 1973$)$

Critieisn conceming state actuity is usually based on the broady defined indicator $\left(G^{\circ}-43.6 \%\right.$ of (NAP) This indieator may be milleading, because donble coming dectrs. It is appropriate to use the brondly defined indicator ondy if it is desired to express that anount of ratimal income, thelinding noone: tary transfers, that flow thromgh government accounts; or - partly $-a s$ an indicator of income redistribuition. If one is interested in the amount of resounces whith are directy absorbed by Goverment expend. fires on goods and serives, the less broadly defined indicator (G - 23.5 percent would be appropriate: Uith respect to the comparative contributions of the public and private sectors on total value added the efen more namowly defined indinator (65. 10.6 percent) is the approphate nedsine.

Moreover refirdless of how the output of the public sector (that is, the stuply of pullic geods) is neismed enticism arises. This occurs becuuse an increasing covernment proportion of GNP does not necessarly reshit in a notiecable increase in Covemnerit ount In additon, Governiment adivity, regardless of how it is neasured, is an inperfect indt cator with respect to the actial supply of public goods, for a nimber of reasons. Price stability, niternat and external security and equal opportunity are Atro public goods but are nor eaptured quantita. Aively in this measure. In adaltion, this measure does

\section{Alternative Measures of Government Spending in the Federal Republic of Germany, $1974^{11}$}

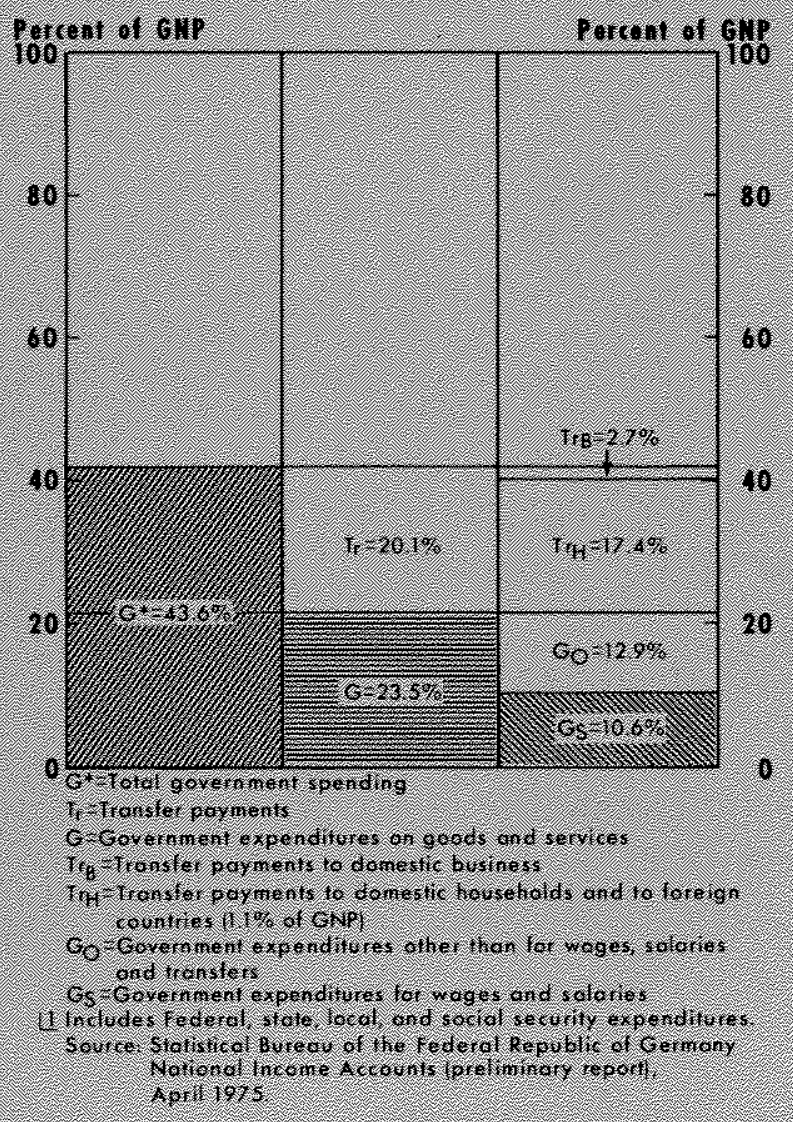

not rellect positive (and negative) extermalites result his fitm Govermment hetivity So far as Goverminent acfuity is included, it is only at prodticer cost, rather than at matket prices. Therefore, it is incorrect to assochite a constantly increasing Government share of CAP with a real ncrease in the supply of public goodl. Eken if it were possible to determine the speciffe rate of infation of government expenditures, the mexsmement of public oufput would still be a prob. len. Therefore, it is not possible to determine either a suffierent tneasure of productivity, or a reliable decomposition of quantity and price components in the public sector.

\section{Normative Approach}

When applied to the political process, the analytical approach to public expenditures, based on price and utility theoretical considerations, is transformed into a normative approach. That is, politicians fix norms and make decisions about priorities. Since the consti-

tution does not specify an objective decisionmaking apparatus and since such an apparatus does not even exist, politicians resort to such guiding principles as some vague notion of increasing public welfare. This is not to say that political decisions are reached without any economic rationale. Rather, economic prin- 
ciples may exist in the background, as a vague guideline, when attempting to achieve the largest possible (social) benefit per unit of money.

The essence of this argument, then, is the following: a continuing and intensive development of a theory of public responsibilities (and expenditures) is necessary - especially a nonmarket decision theory. The application of cost-benefit analysis with respect to (public) infrastructure investments is a case in point. These considerations require a change in emphasis: de-emphasis of the traditionally one-sided study of market relationships and emphasis of political decision processes. This does not mean the substitution of "planning rationale" for "market rationale". What is required, however, is that political decision mechanisms be combined with those of the market. That is, even political decisions ought to be formulated on the basis of prices.

\section{SUMMARY AND CONCLUSTONS}

In Germany the adoption of a socially oriented market economy after World War II proceeded in three phases. The first phase, which featured rapid economic recovery, left numerous social problems unsolved. The following reaction phase led to increased govemment involvement in the economy, as witnessed by progressively increasing government expenditures and numerous restrictions on economic freedom. The present (third) phase of economic development constitutes, to some degree, a counter reaction - criticism and anxiety concerning increasing state activity, and reassessment of the efficiency of a market economy. In evaluating the role of government such cycles can be noticed in other countries as well. Developments in the United States, in this regard, show many parallels with the German case. It is too early to tell, how ever, whether elements of a planned or a market economy will dominate the future economic system in Germany, Independent of specific historic and legal arrangements in individual countries, the determination of an optimal relationship between the private and the public sector constitutes an unsolved problem for all industrial countries of the west.

The magnitude of government expenditures, as contained in the National Income Accounts, do not permit unambiguous assertions with respect to the measurement of government activity. Neither are they a reliable indicator with which to evaluate the supply of public goods as to its optimality. Although, in theory, a social welfare function provides exact criteria for the determination of optimal government activity, it has not been possible to represent the empirically observable counterpart of such a function. Even the construction of social indicators as substitutes for an empirical welfare function is not possible without appealing to value judgments. Thus, as long as it is not possible to develop a comprehensive and empirically meaningful theory of public responsibilities, politicians must necessarily rely on normative, and therefore many times arbitrary, decisions.

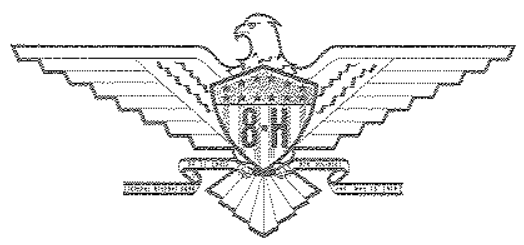

